\title{
Maintaining genetic diversity
}

AMONG the many recommendations of the United Nations Conference on the Human Environment (Stockholm, 1972) which are beginning to bear fruit are those on the conservation of genetic nesources. Registration of bacterial culture collections and seed banks is already under way. Now an Index of Living Plant Collections in the British Isles has been compiled by Dr J. T. Williams (Bentham-Moxon Trust, Royal Botanic Gardens, Kew, 1974). In his introduction to the index Professor Heslop-Harrison says that "the compilation of the present index was not inspired directly by the UN recommendations [having been started before the Stockholm conference] but its intent is wholly consonant with them".

This preliminary index lists institutions with collections of higher plants and collections actively being used in research. It is being distributed worldwide by the International Union for Conservation of Nature and Natural Resources; possibly also by the Food and Agriculture Organisation of the United Nations, as a step towards the ultimate aim of an international register of living plant collections.

of DNA were each proposed as possible causes of $\mathrm{Q}, \mathrm{G}$ and $\mathrm{C}$ banding patterns. Histones however were shown to be partially extracted by fixation and even when they were completely removed by $\mathrm{HCl}$ post-treatment $\mathrm{G}$ banding was not affected (Comings and Avelino, Expl Cell Res., 86, 202; 1974). Similarly, we have observed (Ockey, Nobel Symp., 23, 344; 1972) that removal of histone labelled with tritiated precursors is uncorrelated either negatively or positively with $\mathrm{G}$ or $\mathrm{C}$ banding. Since proteolytic enzymes alone induce $G$ banding and fixation does not seriously denature DNA, differential denaturation was also ruled out as the main cause of $Q$ and $G$ banding. But $C$ banding requires alkali treatment which does induce denaturation with a subsequent rapid renaturation of the highly repetitive DNA sequences in the SSC stage of treatment. Other factors are however involved. Comings and his colleagues (Expl Cell. Res., 77, 469; 1973) and Pathak and Arrighi (Cytogenet. Cell Genet., 12, 414; 1973) both showed that DNA is lost preferentially from the non-C band regions; this may therefore explain their subsequent Giemsa differentiation but by quantitative autoradiography we have observed (unpublished) that when older ${ }^{3} \mathrm{H}$-thymidine labelled preparations are used $C$ bands are visible in many chromosomes that show equal loss of DNA from $\mathrm{C}$ and non- $\mathrm{C}$ band regions.

The C-banding technique is related to the earlier technique of DNA/RNA hybridisation in situ (Pardue and Gall, Science, 168, 1356; 1970) using RNA transcribed from satellite DNA. Both involve the denaturation of DNA and both are supposed to locate constitutive heterochromatin yet there may still be some discrepancies between them. The human Y chromosome has always shown up as constitutive heterochromatin in $\mathrm{C}$ banding but until now had given no indication of repetitive DNA by the hybridisation method. Recently, however, Evans and his colleagues (Nature, 251, 346; 1974) showed that the $\mathrm{Y}$ contained repetitive sequences of all the four AT-rich satellites so far fractionated from human DNA. Constitutive heterochromatin was originally regarded as being ATrich, presumably because satellite DNA was AT-rich but this has been found not to be the rule. Other results have indicated that constitutive heterochromatin regions may react differently to different techniques. Some C-banding sites are non-fluorescent with quinacrine as in the human karyotype, but the $\mathrm{Y}$ chromosome, which also contains $\mathrm{C}$ band repetitive sequences, is the most fluorescent chromosome of the complement. Hoechst 33258, a more recent fluorescent dye, stains the ATrich $\mathrm{C}$ bands in the mouse but not $\mathrm{O}$ bands while in Microtus both typical $\mathrm{Q}$ and $\mathrm{C}$ bands are stained (Hilwig and Gropp, Expl Cell Res., 75, 122; 1972). Facultative heterochromatin (that of the inactive human $\mathrm{X}$ which is represented by the late replicating sexchromatin body in interphase) behaves like the active $\mathrm{X}$ with all known banding techniques, whereas most of the other forms of late replicating heterochromatin can be differentiated by $Q$ and $G$ banding.

It has been proposed that because guanine quenches fluorescence, Q bands must be AT-rich, but this has proved a false trail. Recent work, both with synthetic DNA polymers and with AT-rich satellite DNAs would suggest that the important considerations for quinacrine fluorescence were the sequential arrangement of base pairs, particularly the periodicity of guanine residues which show localised quenching of AT-rich regions, and the availability of binding sites (Selander and de la Chapelle, Nature new Biol., 245, 240; 1973; Weisblum, Nature, 246, 150; 1973). The recent synthetic polymer studies with Hoechst 33258 by Weisblum and Haenssler (Chromosoma, 46, 255 ; 1974) show that fluorescence of this compound is enhanced by both
AT- and GC-rich DNA, enhancement being greater however with AT-rich DNA.

Gottesfeld and his colleagues (Biochemistry, 13, 2937; 1974) have carried these studies a stage further with a detailed biophysical study on separated euchromatin and heterochromatin, and found that quinacrine fluorescence was quenched more with euchromatin than with heterochromatin. The DNA extracted from these fractions however showed similar AT/ $\mathrm{GC}$ base ratios and a similar fluorescence. They suggest from circular dichroism spectroscopy studies that heterochromatin DNA probably exists in the $\mathbf{B}$ configuration while euchromatin shows the $\mathrm{C}$ form. It is interesting to note in this connection that the conformation of AT-rich DNA in bacteria varies very much in its configuration with relative humidity and over a narrow range of ionic strength of $\mathrm{NaCl}$ (Bram and Tougard, Nature new Biol., 239, 128; 1972), both of which are critical factors in banding.

The incorporation of base analogues into DNA also affects the staining behaviour of chromosomes. Zakharov and his colleagues (Chromosoma, 44, 343; 1974) have found a considerable reduction in chromosome spiralisation at metaphase in regions which incorporate bromodeoxyuridine (BrdU) and $\mathrm{BrdC}$ during the latter period of the $\mathrm{S}$ phase when heterochromatin is replicating. No such differential spiralisation was observed when the analogue was incorporated into the early replicating euchromatin, implying a difference in conformation of the DNA between the two forms of chromatin as suggested by Gottesfeld and his group.

Latt (Science, 185, 74; 1974) showed that $\mathrm{BrdU}$, incorporated semiconservatively over two cell cycles, resulted in one of the chromatids showing strong fluorescence (monofilial incorporation), the other (bifilial incorporation) weak fluorescence using the dye Hoechst 33258. Latt explained this difference as a quenching in the bifilial chromatid with less or no quenching in the monofilial BrdU chromatid. This technique provides a valuable tool in analysis of sister-chromatid exchanges (Kato, Nature, 251, 70; 1974). Perry and Wolff (Nature, 251, 156; 1974) were able to obtain a permanent differential staining of chromatids following SSC treatment after BrdU incorporation and subsequent Giemsa staining. The bifilial chromatid was less intensely stained and less condensed that its sister. These results they suggest are probably due to a difference in protein binding to BrdU-containing DNA. They also obtained differential fluorescence with acridine orange in the two chromatids.

Bobrow and Gross (Nature, 251, 77; 